\title{
A fatal case by a suicide kit containing sodium nitrite ordered on the internet
}

\author{
Carlos Durão $^{\mathrm{a}, \mathrm{b}}$, Frederico Pedrosa ${ }^{\mathrm{a}}$, Ricardo Jorge Dinis-Oliveira ${ }^{\mathrm{c}, \mathrm{d}, \mathrm{e}, *}$ \\ ${ }^{\text {a }}$ Portuguese National Institute of Legal Medicine and Forensic Sciences, Lisbon, Portugal \\ ${ }^{\mathrm{b}}$ Hospital Vila Franca de Xira, Vila Franca de Xira, Portugal \\ ${ }^{\mathrm{c}}$ IINFACTS - Institute of Research and Advanced Training in Health Sciences and Technologies, Department of Sciences, University Institute of Health Sciences (IUCS), \\ CESPU, CRL, Gandra, Portugal \\ ${ }^{\mathrm{d}}$ Department of Public Health and Forensic Sciences, Medical Education, Faculty of Medicine, University of Porto, Porto, Portugal \\ ${ }^{\mathrm{e}}$ UCIBIO-REQUIMTE, Laboratory of Toxicology, Department of Biological Sciences, Faculty of Pharmacy, University of Porto, Porto, Portugal
}

\section{A R T I C L E I N F O}

\section{Keywords:}

"Suicide kit"

Sodium nitrite

Poisoning

Crime scene

Suicide

\begin{abstract}
A B S T R A C T
Fatal sodium nitrite poisonings are rare in the forensic context. The present work describes a first fatal case of sodium nitrite contained in a suicide kit that the victim acquired over the internet. The results of the autopsy showed general signs of asphyxia, such as intense cyanosis of the extremities, brown-gray-blue-red livor mortis, and some Tardieu petechiae in addition to intense visceral congestion. It is clear that forensic experts must be aware of the proliferation of this market and the risks of improper selling of these substances through suicide support networks available on the internet. The lack of knowledge of this reality may become unidentifiable, when toxicological analysis contemplates only the most classical and frequent substances involved in poisoning and reinforce the importance of a careful analysis of the death scene.
\end{abstract}

\section{Introduction}

Sodium nitrite $\left(\mathrm{NaNO}_{2}\right)$ is an easily accessible food additive (i.e., E250), widely used as preservative, antimicrobial agent by inhibiting effect of Clostridium botulinum, an anaerobic bacteria responsible for botulism, and by its capacity to fix the pink color of the cured meat and fish and some cheeses. ${ }^{1}$ Sodium nitrite is also used as antifreeze admixture and to prevent corrosion of pipes and tanks, ${ }^{2}$ as an antidote for cyanide poisoning ${ }^{3}$ and it is a proved carcinogen since nitrites react with amines and amides to form nitrosamines. ${ }^{4}$

While non-lethal intoxications by contaminated water and food is widely reported, lethal cases are rarely described. ${ }^{5-9}$ The estimated lethal dose of sodium nitrite in adults is approximately $2.6 \mathrm{~g},{ }^{10,11}$ but survival was also reported for ingestion of $6 \mathrm{~g}$ sodium nitrite. ${ }^{1}$ This work presents the first case described in the literature of a suicide by sodium nitrite after ordering a "suicide kit" on the internet.

\subsection{Case report}

A 37-year-old man was found dead inside his car next to a box that contained two glass cups, the medicines Primperan ${ }^{\circledR}$ (i.e., metoclopramide, $10 \mathrm{mg}$ ) and ranitidine $(75 \mathrm{mg}$ ) and a $35 \mathrm{~g}$ package of crystalline sodium nitrite (Fig. 1). The social investigation revealed that the victim, who suffered from depression and schizophrenia, previously attempted suicide and recently consulted suicide support websites on the internet.

The most relevant autoptic findings were the general signs of asphyxia, such as intense scleral congestion (Fig. 2A) and cyanosis of the extremities (Fig. 2B), namely hands and lips, and brown-gray-blue-red livor mortis in various parts of the body (Fig. 2C), some Tardieu petechiae in addition to intense polyvisceral congestion. The blood was tinted a chocolate brown color. Histological examination revealed only nonspecific changes, such as pulmonary edema and coronary artery disease without major expression.

The initial toxicological analysis, by gas and liquid chromatography both coupled to mass spectrometry, in femoral blood showed concentrations of desmethylcitalopram $90 \mathrm{ng} / \mathrm{mL}$, citalopram $252 \mathrm{ng} / \mathrm{mL}$ and trazodone $280 \mathrm{ng} / \mathrm{mL}$ and negativity for other substances investigated. However, considering the evidence found at the crime scene, the femoral blood and gastric content were reanalyzed with a specific spectrophotometric methodology for sodium nitrite. Briefly, the method was based

\footnotetext{
* Corresponding author. IINFACTS - Institute of Research and Advanced Training in Health Sciences and Technologies, Department of Sciences, University Institute of Health Sciences (IUCS), CESPU, CRL, Rua Central de Gandra, 1317, Gandra, 4585-116, Portugal.

E-mail address: ricardinis@sapo.pt (R.J. Dinis-Oliveira).
} 

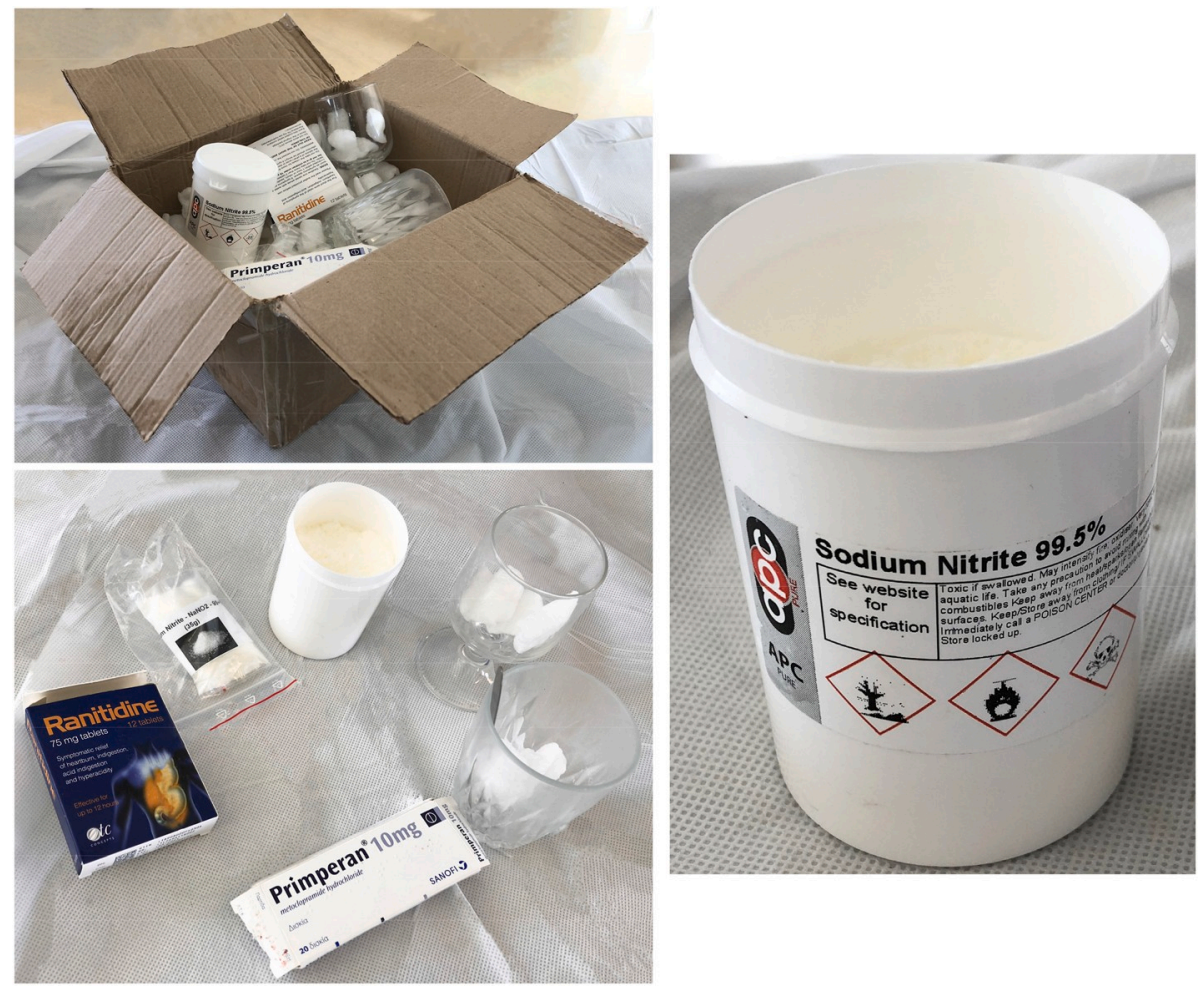

Fig. 1. "Suicide kit" ordered by the internet found at the death scene next to the victim. It contained glasses to ingest the sent medicines (i.e., Primperan ${ }^{\circledR}$ and ranitidine) and a sodium nitrite packet of $99.5 \%$ contained inside a plastic flask.
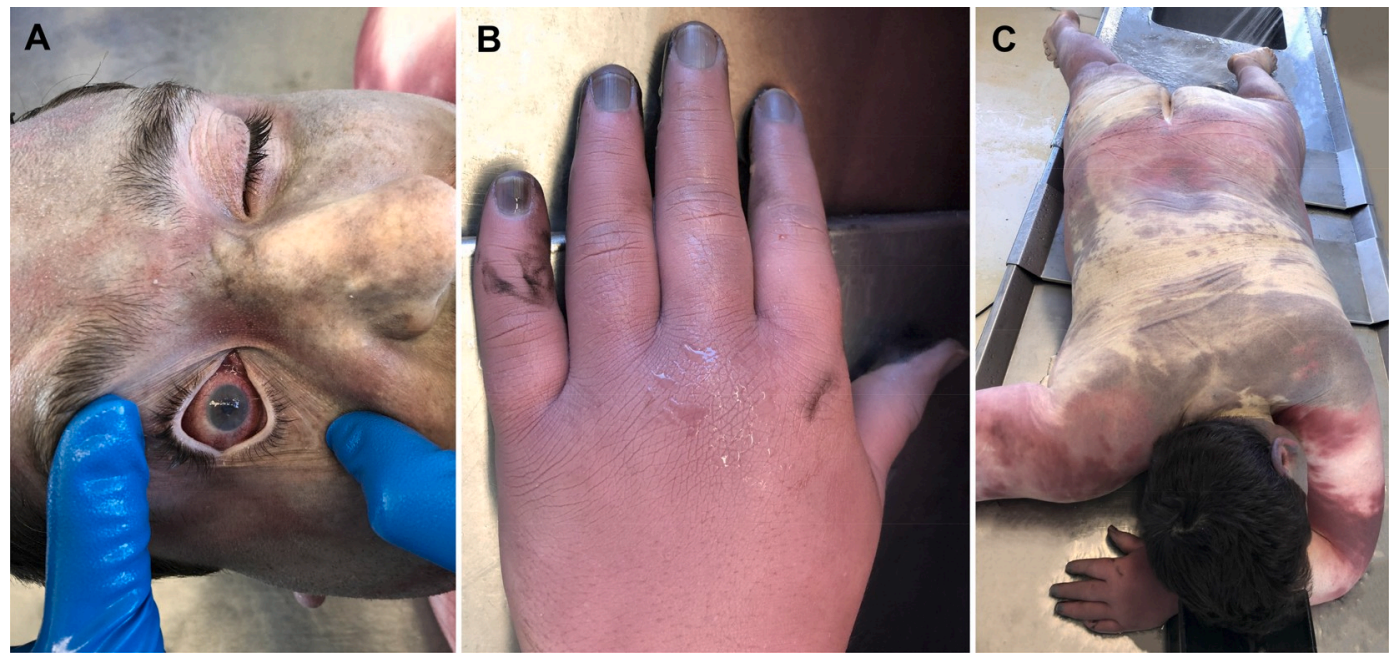

Fig. 2. Autopsy findings revealed general signs of asphyxia, with marked congestion of the sclera (A), cyanosis of the digital extremities (B) and a brown-gray-bluered livor mortis (C). (For interpretation of the references to color in this figure legend, the reader is referred to the Web version of this article.)

on a diazotization-coupling reaction between dapsone and $N$-(1-naphthyl)ethylenediamine in a hydrochloric acid medium. ${ }^{12}$ In the gastric content $16 \mathrm{~g} / \mathrm{L}$ of nitrites and $24 \mathrm{~g} / \mathrm{L}$ of sodium nitrite were obtained. In blood $30 \mathrm{ng} / \mathrm{mL}$ of nitrites were obtained.

\section{Discussion}

Sodium nitrite is a white crystalline powder with a similar appearance to kitchen salt, easily soluble in water, which eventually allows it to also be used in homicidal form concealed in drinks. ${ }^{13}$ Searching on the internet some websites advertise that: i) "sodium nitrate offers a number of features that make it an ideal human euthanasia agent. It is cheap, breaks down readily in the environment"; ii) "this is the secret powder to help old people who have a fulfilled life who are not terminally ill and want to die in a peaceful way. Only $2 \mathrm{~g}$ of the powder are needed." Besides sodium cyanide and sodium azide, sodium nitrite due to its availability, preparation, un-detectability, speed, safety, and storage is advocated to be peacefulness suicide method. ${ }^{14}$

Sodium nitrite causes asphyxia, since hemoglobin is oxidized to methemoglobin, precipitating methemoglobinemia. In other words, as an oxidizer, nitrite can convert the ferrous iron $\left(\mathrm{Fe}^{2+}\right)$ of hemoglobin to ferric iron $\left(\mathrm{Fe}^{3+}\right)$, forming methemoglobin, and thereby impairing oxygen transport. Similarly to carbon monoxide poisonings, due to the allosteric changes of hemoglobin, a left shift to the oxygen-hemoglobin 
dissociation curve occurs, increasing the affinity of hemoglobin to oxygen resulting in an impairment of oxygen delivery to the tissues and thus a vital anemic hypoxemia builds. ${ }^{10,15,16}$ Bradyasystolic cardiac arrest usually rapidly develops. ${ }^{5}$ Symptoms such as nausea, vomiting, lethargy, shortness of breath, convulsions and coma are evident soon after intoxication, especially if levels of methemoglobinemia are higher than $60 \% .{ }^{17}$ Methemoglobinemia levels above $70 \%$ usually proved to be fatal, but cases of survival with levels up to $94 \%$ have been reported. ${ }^{18,19}$

In our case, autopsy results revealed brown/gray/blue/red livor mortis in various anterior and posterior parts of the body, namely lips, hands, and shoulders. It is suggested to be an adverse consequence of the vasodilation, since sodium nitrite is an precursor of nitric oxide. ${ }^{19,20}$ Curiously, due to the increase of the blood flow, compounds such as sodium nitrite/nitrate have been subject to patent protection for performance enhancement in sport. ${ }^{21}$ The brown color of the livor mortis is one of the major textbook signs of nitrite poisoning that can help to suspect about this poisoning. Nevertheless, the lack of this sign in some cases can be attributed to a low concentration of methemoglobin at the time of death. ${ }^{9}$ The classical chocolate colored-blood was slightly present in our case. Moreover, one of the most characteristic postmortem change was the blue-gray discoloration of the fingernail beds as signs of hypoxia due to methemoglobinemia.

The toxicological tests revealed increased nitrite ion levels in the blood and gastric contents. In other studies, methemoglobinemia of $9.87 \%$ and $24.6 \mathrm{ng} / \mathrm{mL}$ of nitrites in the blood, $93.91 \mathrm{mg} / \mathrm{kg}$ in the stomach contents, and $0.003 \mathrm{mg} / \mathrm{kg}$ in the liver and kidney mixture were reported. ${ }^{9}$ Blood nitrite levels in death cases following accidental or intentional ingestion were reported to be $0.55-13 \mu \mathrm{g} / \mathrm{mL} .^{22,23}$ Methemoglobin concentrations were not analyzed in our case. An enzyme-linked immunosorbent assay (ELISA) kit, following the manufacturer's instructions would be useful, but higher values than the reference range (1-2\%) were suspected. ${ }^{24}$ In some deaths, sodium nitrite was detected in gastric contents but not in other body fluids or tissues. ${ }^{25}$ Therefore, as previously suggested, if the presence of nitrite is suspected in the blood, quantification of the methemoglobin levels may be more important than the nitrite or nitrate levels. Moreover, since in some cases nitrate levels were much higher than nitrite levels, the former should also be quantified. ${ }^{11,26}$ Indeed, in comparison to our results, similar nitrite levels $(<0.05$ and $0.09 \mu \mathrm{g} / \mathrm{mL}$ in cardiac and femoral blood, respectively) were also reported, for which nitrate levels (71.69 and $83.48 \mu \mathrm{g} / \mathrm{mL}$ in cardiac and femoral blood, respectively) were significantly high. ${ }^{26}$ The justification could be due to nitrite conversion to nitrate, which is incapable of oxidizing hemoglobin to methemoglobin in the body. ${ }^{26}$ Importantly, since nitrites and nitrates are not substances commonly analyzed in forensic toxicology services, false negative results of intoxication may be obtained. Metoclopramide and ranitidine were not detected in toxicological analysis. Although speculative, we hypothesized that these drugs are included in the suicide kit to reduce emesis and therefore to increase ingestion and tolerance to sodium nitrite. ${ }^{27,28}$

In conclusion, based on the results of the forensic, toxicological, and death scene investigation, the cause of death was due asphyxia resulting from methemoglobinemia induced by sodium nitrite overdose. Although, poor health condition or pre-existing disease, such as anemia, acidosis, respiratory compromise, and cardiac disease, increases the susceptibility to the fatal consequences of nitrite poisoning, ${ }^{9}$ autopsy did not reveal any remarkable signs of previous disease. It is also important to highlight that besides sodium nitrite intoxications, methemoglobinemia may arise from a variety of etiologies including genetic, dietary, idiopathic, and methyl nitrite intoxications. ${ }^{2,29-31}$ The treatment of severe methemoglobinemia usually focus on aggressive decontamination, hyperoxic ventilation, and administration of reducing substances such as the thiazine dye methylene blue. ${ }^{10}$ Failure to detect sodium nitrite in routine toxicological analysis can result in false negatives. In this regard, the inclusion of methemoglobin, nitrite and nitrate quantification should be considered if crime scene is particularly suggestive. This case also reveals the danger and the importance of preventing and fighting existing suicide support networks over the internet, which allow the purchase of a "suicide kit", by circumvent the customs services.

\section{Funding}

The authors have no relevant affiliations or financial involvement with any organization or entity with a financial interest in or financial conflict with the subject matter or materials discussed in the manuscript. The potential conflicts include employment, consultancies, honoraria, stock ownership or options, expert testimony, grants or patents received or pending, and royalties.

\section{Ethical approval}

All procedures were performed according to the ethical and legal standards of the institution and the principles of the Declaration of Helsinki. This study did not require informed written or oral consent from the victims' families since this is a scientific research conducted during routine forensic procedures.

\section{Informed consent}

Not applicable.

\section{Declaration of competing interest}

The authors have no conflicts of interest to declare. No writing assistance was obtained in the production of this manuscript.

\section{References}

1. Chui JS, Poon WT, Chan KC, Chan AY, Buckley TA. Nitrite-induced methaemoglobinaemia - aetiology, diagnosis and treatment. Anaesthesia. 2005;60 496-500.

2. Farkas AN, Scoccimarro A, Pizon AF. Methemoglobinemia due to antifreeze ingestion. N Engl J Med. 2017;377:1993-1994.

3. Bebarta VS, Brittain M, Chan A, et al. Sodium nitrite and sodium thiosulfate are effective against acute cyanide poisoning when administered by intramuscular injection. Ann Emerg Med. 2017;69, 718-25.

4. Kalaycioglu Z, Erim FB. Nitrate and nitrites in foods: worldwide regional distribution in view of their risks and benefits. J Agric Food Chem. 2019;67: 7205-7222.

5. Harvey M, Cave G, Chanwai G. Fatal methaemoglobinaemia induced by selfpoisoning with sodium nitrite. Emerg Med Australasia (EMA). 2010;22:463-465.

6. Saito T, Takeichi S, Yukawa N, Osawa M. Fatal methemoglobinemia caused by liniment solutions containing sodium nitrite. J Forensic Sci. 1996;41:169-171.

7. Saito T, Takeichi S, Osawa M, Yukawa N, Huang XL. A case of fatal methemoglobinemia of unknown origin but presumably due to ingestion of nitrate. Int J Leg Med. 2000;113:164-167.

8. Ellis M, Hiss Y, Shenkman L. Fatal methemoglobinemia caused by inadvertent contamination of a laxative solution with sodium nitrite. Isr J Med Sci. 1992;28: 289-291.

9. Cvetkovic D, Zivkovic V, Lukic V, Nikolic S. Sodium nitrite food poisoning in one family. Forensic Sci Med Pathol. 2019;15:102-105.

10. Wright RO, Lewander WJ, Woolf AD. Methemoglobinemia: etiology, pharmacology, and clinical management. Ann Emerg Med. 1999;34:646-656.

11. Lee C, Jang EJ, Yum H, Choi YS, Hong J. Unintentional mass sodium nitrite poisoning with a fatality. Clin Toxicol. 2017;55:678-679.

12. Wang Y, Townsend MK, Eliassen AH, Wu T. Stability and reproducibility of the measurement of plasma nitrate in large epidemiologic studies. N Am J Med Sci. 2013;6:82-86.

13. Tung SP, How CK, Chern $\mathrm{CH}$. Methaemoglobinaemia secondary to the ingestion of sodium nitrite in mistake for common salt. Resuscitation. 2006;70:168-169.

14. Nitschke P, Stewart F. The Peaceful Pill Handbook. Waterford: Exit International US; 2007.

15. Valente-Aguiar MS, Magalhaes T, Dinis-Oliveira RJ. Suicide by inhalation of carbon monoxide of car exhausts fumes. Curr Drug Res Rev. 2019;11:145-147.

16. Dinis-Oliveira RJ, Carvalho F, Magalhães T, Santos A. Postmortem changes in carbon monoxide poisoning. Clin Toxicol. 2010;48:762-763.

17. Katabami K, Hayakawa M, Gando S. Severe Methemoglobinemia Due to Sodium Nitrite Poisoning. Case Reports in Emergency Medicine. 2016, 2016:9013816.

18. Edwards RJ, Ujma J. Extreme methaemoglobinaemia secondary to recreational use of amyl nitrite. J Accid Emerg Med. 1995;12:138-142.

19. Bradberry SM, Whittington RM, Parry DA, Vale JA. Fatal methemoglobinemia due to inhalation of isobutyl nitrite. J Toxicol Clin Toxicol. 1994;32:179-184. 
20. Petroczi A, Naughton DP. Potentially fatal new trend in performance enhancement: a cautionary note on nitrite. J Int Soc Sports Nutr. 2010;7:25.

21. Petroczi A, Naughton DP. Popular drugs in sport: descriptive analysis of the enquiries made via the Drug Information Database (DID). Br J Sports Med. 2009;43: 811-817.

22. Standefer JC, Jones AM, Street E, Inserra R. Death associated with nitrite ingestion: report of a case. J Forensic Sci. 1979;24:768-771.

23. Gowans WJ. Fatal methaemoglobinaemia in a dental nurse. A case of sodium nitrite poisoning. Br J Gen Pract. 1990;40:470-471.

24. Prchal JT, Gregg XT. Red cell enzymes. Hematology Am Soc Hematol Educ Program. 2005:19-23.

25. Barton GM. A fatal case of sodium nitrite poisoning. Lancet. 1954;266:190-191.

26. Nishiguchi M, Nushida H, Okudaira N, Nishio H. An autopsy case of fatal

methemoglobinemia due to ingestion of sodium nitrite. J Forensic Res. 2015;6:262.
27. Cozanitis D, Asantila R, Eklund P, Paloheimo M. A comparison of ranitidine, droperidol or placebo in the prevention of nausea and vomiting after hysterectomy. Can J Anaesth. 1996;43:106-109.

28. Patanwala AE, Amini R, Hays DP, Rosen P. Antiemetic therapy for nausea and vomiting in the emergency department. J Emerg Med. 2010;39:330-336.

29. Methemoglobinemia following unintentional ingestion of sodium nitrite-New York. MMWR Morb Mortal Wkly Rep. 2002;51:639-642, 2002.

30. Huang S, Wang R, Guo B, et al. Fatal methemoglobinemia due to acute inhalation of methyl nitrite in an industrial accident. J Forensic Sci. 2020. https://doi.org/ 10.1111/1556-4029.14275. In press.

31. Warren OU, Blackwood B. Acquired methemoglobinemia. N Engl J Med. 2019;381: 1158 